\title{
GUILLIAN BARRE SYNDROME;
}

VARIOUS CLINICAL FEATURES OF GUILLIAN BARRE SYNDROME IN PATIENTS PRESENTING TO A TERTIARY CARE HOSPITAL IN KARACHI.

\footnotetext{
1. MBBS, FCPS. Neurology Assistant Professor Department of Neurology JPMC Karachi.

2. MBBS, FCPS. Neurology Assistant Professor Department of Neurology JPMC / JSMU Karachi.

3. MBBS, FCPS. Neurology Assistant Professor Department of Neurology SMBBMC Lyari Karachi.

4. MBBS

Registrar

Neurology Department JPMC, Karachi

5. MBBS, FCPS Assistant Professor Neurology Department JPMC, Karachi

6. MBBS

Medical Officer JPMC, Karachi
}

\section{Corresponding Address:}

Dr. Shahid lqbal

Department of Neurology

JPMC Karachi.

suneelk78@yahoo.com

Article received on:

13/04/2018

Accepted for publication:

25/11/2018

Received after proof reading:

$31 / 01 / 2019$

\begin{abstract}
Shahid Iqbal ${ }^{1}$, Naeemullah Bullo ${ }^{2}$, Dileep Kumar ${ }^{3}$, Suneel Kumar ${ }^{4}$, Munir Afzal ${ }^{5}$, Vikash $^{6}$
ABSTRACT... Objectives: To determine the frequency of various clinical features of Guillian Barre Syndrome in patients presenting to a tertiary care hospital in Karachi. Study Design: Descriptive study. Period: July 2015 to December 2015. Setting: Tertiary care hospitals of Karachi. Material \& Methods: Seventy five diagnosed case of GBS who fulfill the inclusion criteria irrespective of gender included in the study after informed consent. Data was collected on preformed proforma. Detailed history, physical examination was done on each patient, diagnosis was confirmed on NCV \& EMGs. Data analysis procedure was done with the help of SPSS version 16. Mean \pm SD was calculated for age of the patient and duration of clinical features. Frequency and percentages were calculated for different clinical features. Stratification was done with respect to age, gender and duration of clinical features to control effect modifiers in the study. Results: Mean age was $43.96 \pm 14.22$ (ranging from 15 to 70 ) years, among 75 patients $51(68 \%)$ were male \& $24(32 \%)$ were female, majority of patients (34) were $>50$ years of age, $45.3 \%$ of patients had pain in extremities; pain in back was reported by $49.3 \%$. Dysphagia in $80 \%$, Ophthalmoplegia in $20 \%$ and Dysarthria in $16 \%$ of patients Respiratory failure was prevalent in $34.7 \%$ patients. Sinus tachycardia occurred in $49.3 \%$, Sinus bradycardia $14.7 \%$ patients and $20 \%$ patients had urinary dysfunction. Constipation was also a predominant feature affecting $80 \%$ of patients. Conclusion: We found that GBS occurred at all ages and was more common in males. There are various clinical features of GBS along with flaccid limbs weakness clinical features observed \& these should be address promptly for better outcome.
\end{abstract}

Key words: $\quad$ Guillian Barre Syndrome, Clinical Features, Dysphagia.

Article Citation: Iqbal S, Bullo N, Kumar D, Kumar S, Afzal M, Vikash. Various clinical features of guillian barre syndrome in patients presenting to a tertiary care hospital in Karachi. Professional Med J 2019; 26(2):292-298.

DOI: 10.29309/TPMJ/2019.26.02.3107
INTRODUCTION

Guillian -Barre syndrome recognized as the commonest cause of acute post infectious flaccid paralysis world wide ${ }^{1}$ with an estimated worldwide incidence of 1.1-1.8/100,000 persons and has been associated with $\$ 1.7$ billion in yearly costs in the United States alone..$^{2-3}$ Cases range from mild to severe disease and recovery depends on disease severity. Symptoms usually take 6 to 18 months to fully resolve, although a small proportion may require prolonged hospitalization or care. ${ }^{4-5}$ The association between GBS and antecedent infection has been well described, the most common infectious triggers including campylobacter jejuni, haemophilus influenza, mycoplasma pneumonia, Epstein barr virus, cytomegalo virus \& hepatitis E. ${ }^{6,7}$ Interestingly, C. jejuni-associated GBS may be associated with a more severe clinical presentation. ${ }^{8,9}$ The common clinical features of GBS found Pain in extremities $50 \%$, pain in back $42.3 \%$, dysphagia $50 \%$, ophthalmoplegia $23.3 \%$, decreased gag reflex $20 \%$, dysarthria $16.7 \%$, ptosis $16.7 \%$, respiratory failure requiring intubation $55.9 \%$, sinus tachycardia $47.6 \%$, sinus bradycardia $14.3 \%$, urinary dysfunction $28.6 \%$ and constipation $88.2 \% .{ }^{10}$ Despite modern treatment 3\% of patients with GBS still die \& $20 \%$ are left severely. ${ }^{11}$ GBS have various clinical features along with flaccid weakness of limbs for this we gathered the data to find out the frequency of these various clinical features in this study.

\section{MATERIAL AND METHODS Study Design \\ Descriptive Case Series study}


Setting

Neurology Department at JPMC Karachi.

Duration of Study

July2015 to December 2015

\section{Sample Size}

75

\section{Sampling Technique}

Non-probability consecutive sampling

\section{Inclusion Criteria}

Patients with diagnosis of GBS

GBS of $<4$ weeks duration

Either genders of $>15 y e a r s$

\section{Exclusion Criteria}

Known case of BPH, lead neuropathy, Botulism, poliomyelitis, hysterical paralysis

History of diphtheria infection

Pronounced asymmetry of weakness

Purely sensory symptoms

\section{Data Collection}

Patients diagnosed with GBS were enrolled in the study. Verbal informed consent was taken prior to enrollment in study. History taking and examination was done by the researcher himself to assess the clinical features. The focus was made on common clinical features like Pain extremities, pain in back, dysphagia, Ophthalmoplegia, decreased gag reflex, dysarthria, ptosis, respiratory failure requiring intubation, Sinus tachycardia, Sinus bradycardia, urinary dysfunction and constipation.

\section{Data Analysis}

Data analysis procedure was done with the help of SPSS version 16. Mean \pm SD was calculated for age of the patient and duration of clinical features. Frequency and percentages were calculated for Pain extremities, pain in back, dysphagia, Ophthalmoplegia, decreased gag reflex, dysarthria, ptosis, respiratory failure requiring intubation, Sinus tachycardia, Sinus bradycardia, urinary dysfunction and constipation. Stratification was done with respect to age, gender and duration of clinical features to control effect modifiers in the study.

\section{RESULTS}

Out of 75 patients of GBS mean age was $43.96 \pm 14.22$ (ranging from 15 to 70 ) years. Among 75 patients, 4 (5.3\%) were of 20 years or below, 12 (16\%) had 21-30 years, 11 (14.7\%) had $31-40$ years, $14(18.7 \%)$ had $41-50$ years and 34 had their age $>50$ years as shown in Figure-1. Among 75 patients, 51 (68\%) were males and 24 (32\%) were female with 2.1: 1 male to female ratio Figure-2. Majority of the patients of GBS presented with clinical features within 1 week i.e. $60(80 \%)$ followed by $10(13.3 \%)$ during the second week, $3(4 \%)$ during the third week and $2(2.67 \%)$ patients presented in the fourth week from the onset of symptoms of the clinical features of GBS Figure-3. Out of 75 patients, 34 $(45.3 \%)$ had pain extremities, Pain in back was reported by 37 (49.3\%) patients, Dysphagia was found in 60 (80\%) patients, Ophthalmoplegia was seen in $15(20 \%)$ patients, Dysarthria was found in $12(16 \%)$ patients, Eight (10.7\%) patients had ptosis, Respiratory failure was prevalent in 26 $(34.7 \%)$ patients, Sinus tachycardia occurred in 37 (49.3\%) patients, Sinus bradycardia occurred in 11 (14.7\%) patients, Fifteen (20\%) patients had urinary dysfunction, Sixty (80\%) patients reported complaint of constipation, Among 4 patients of age $<20$ years, they had multiple features as all had dysphagia, sinus tachycardia and constipation and $3(75 \%)$ had respiratory failure as additional feature while in 12 patients of age 21-30 years, constipation was the predominant clinical feature followed by pain extremities, pain in back, dysphagia and sinus tachycardia with $50 \%$ each. Among 11 patients of age 31-40 years, constipation, dysphagia and sinus tachycardia were again predominant clinical features. Among 14 patients of age 4150 years, constipation, dysphagia, pain in back and sinus tachycardia were the most frequent features while in 34 patients of age $>50$ years, had multiple but mixed pattern of involvement of clinical features however, pain extremities, dysphagia, constipation, respiratory failure, pain in back and urinary dysfunction were the highly prevalent features (Table-I). The proportions of clinical features of constipation, dysphagia and 
sinus tachycardia were higher in the males than females however pain in back, pain extremities, ptosis, sinus bradycardia, respiratory failure and urinary dysfunction were more prevalent among females than males (Table-II). Five patients who presented in the third and fourth weeks from the onset of symptoms, they had pain extremities and pain in back \& in 10 patients who presented in the second week, pain in back and ptosis were the dominant clinical features while the majority of the patients who presented within week had multiple and severe type of clinical features (Table-III).

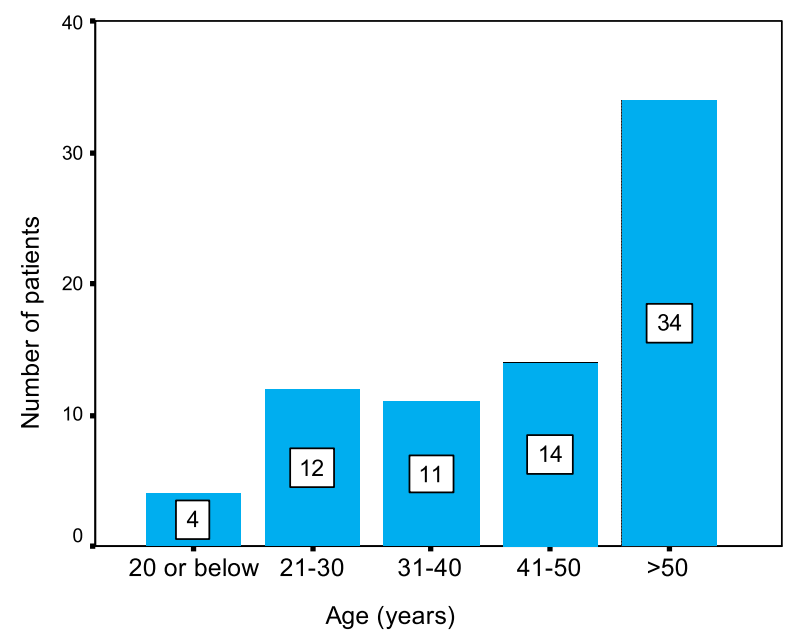

Figure-1. Age distribution: $\mathrm{n}=75$ Mean $\pm S D=43.96 \pm 14.22$ (ranging from 15 to 70 ) years
Female

$24 / 32 \%$

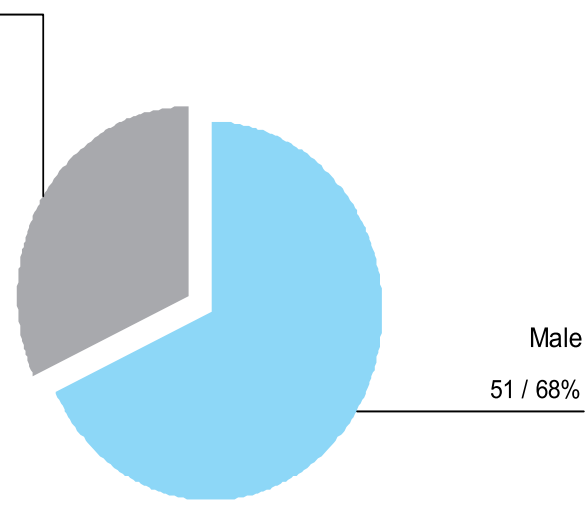

Figure-2. Gender distribution: $\mathbf{n}=75$

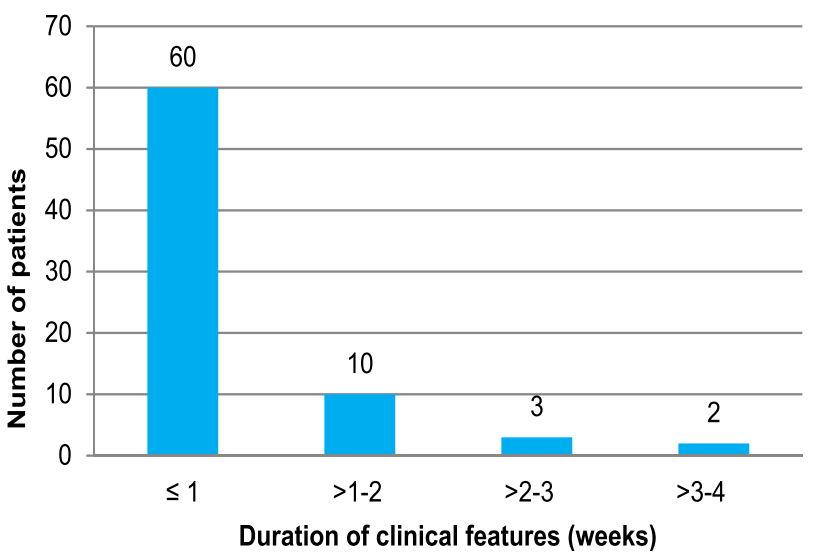

Figure-3. Duration of clinical features: $n=75$

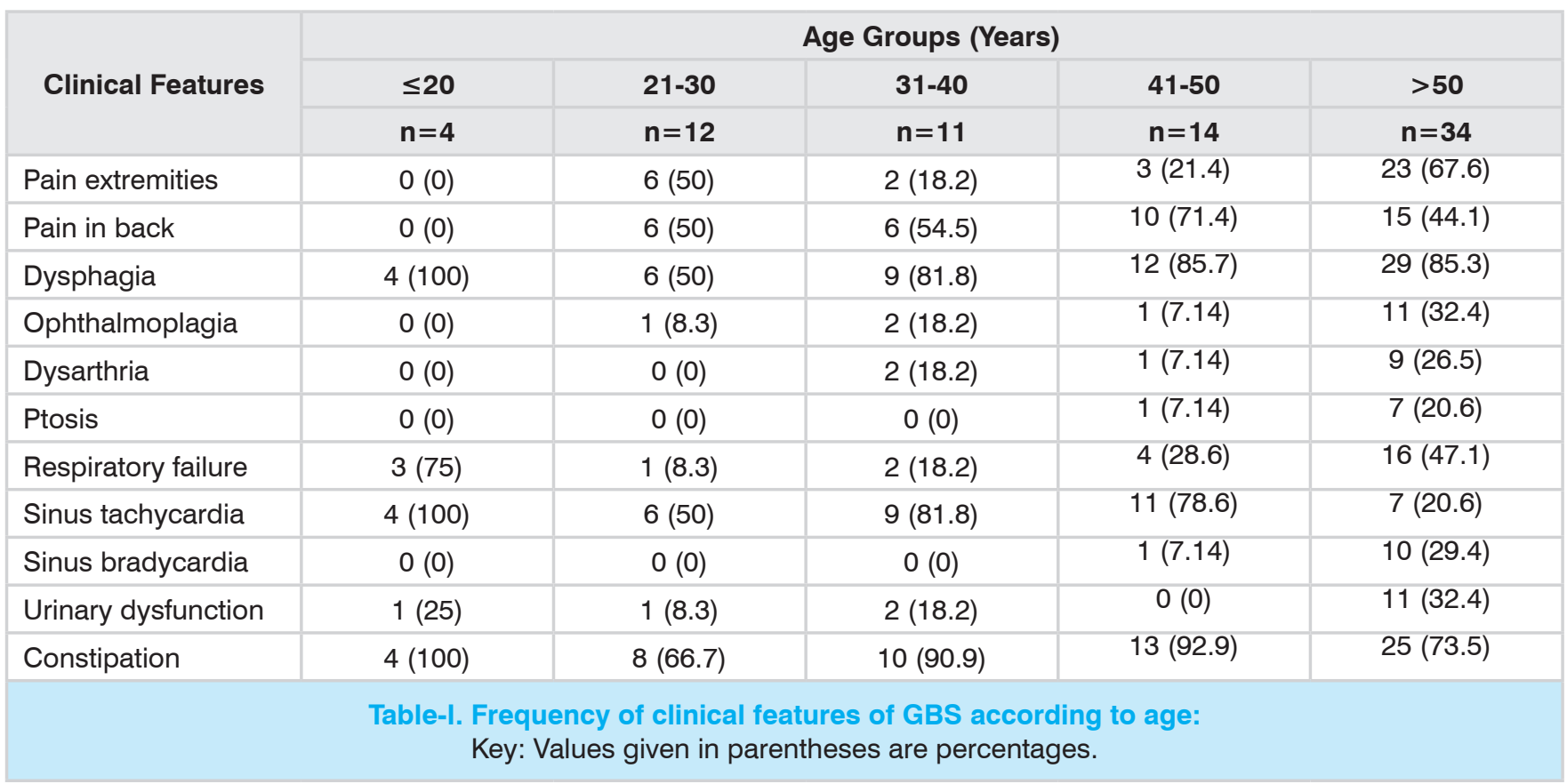




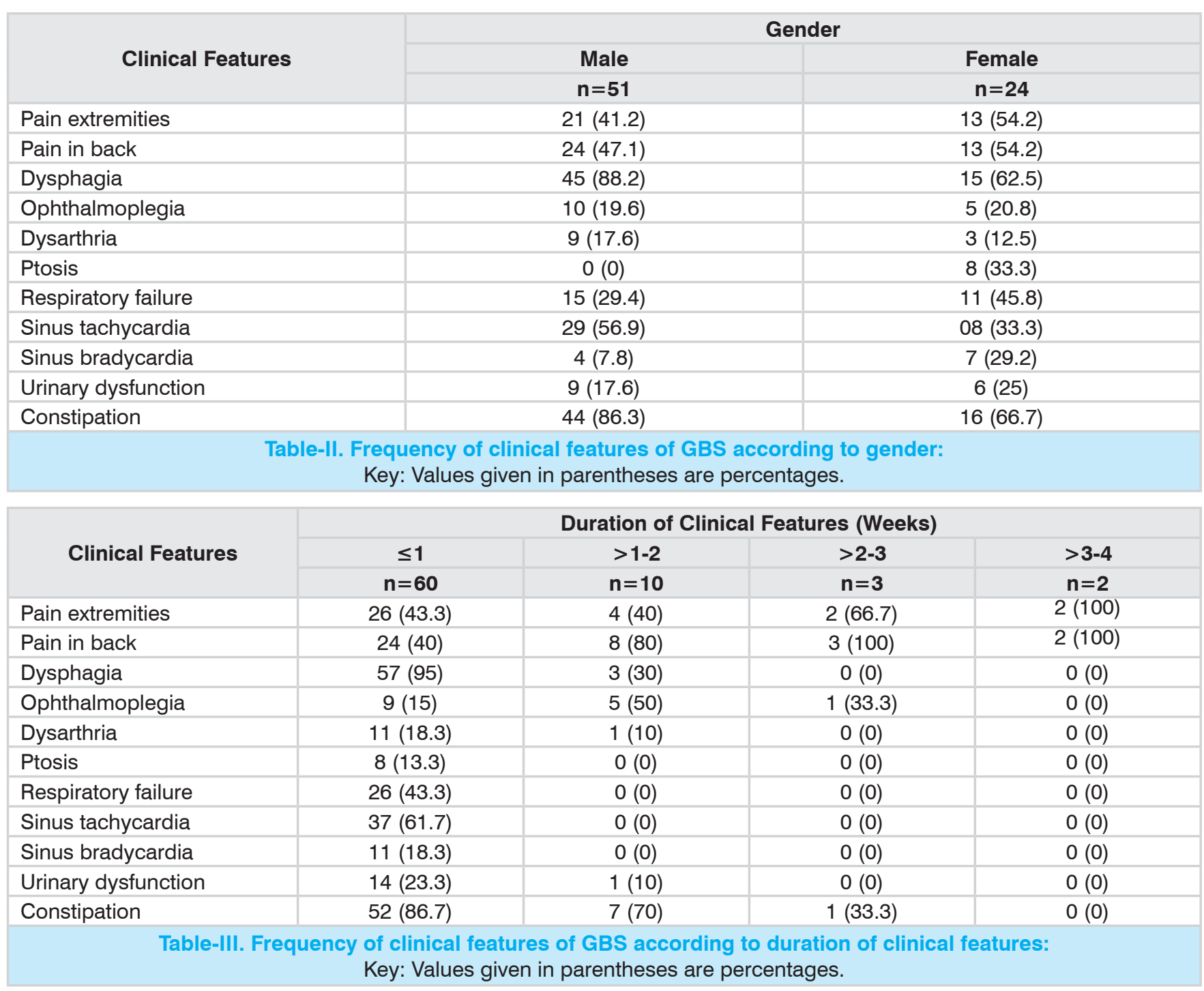

\section{DISCUSSION}

The Guillian Barre syndrome being a rare disorder has little data available from Pakistan and also because health facilities are poor in remote areas of the country it can be estimated that many patients remain undiagnosed which is further reducing availability of scientific data. In this study we recorded 75 patients who were diagnosed as having Guillian Barre Syndrome according to the Asbury criteria. Our study showed male to female ration of 2:1.1 thus proving male preponderance which is similar to other studies done in Asia. ${ }^{12,13}$ However our male population was slightly higher and earlier a similar study in Karachi by Yawar et al demonstrated 1.6:1 male to female ratio. ${ }^{14}$ Our study showed increasing incidence of GB syndrome in adults $>20$ years of age which is in accordance with most asian and western studies and peak incidence was noted in adults over 50 years of age..$^{15,16}$ No preponderance was noted in any particular ethnic group. Seasonal variation has not been reported in most studies ${ }^{17,18}$ but there is data which has shown increased occurrence of GB syndrome in winter and autumn. ${ }^{19,20}$ Our study was done in a very limited period of only 6 month and no preponderance of cases was noted in any particular month, although the study began in summers and ended in December which marks the coldest season in Karachi and adjoining areas. Possibly if the duration of study was larger it would have been possible to find increasing incidence in any particular season. One of the major limitations of the study was that we could not focus the predisposing factors leading to GBS 
like gastrointestinal infections and respiratory tract infections as reported by Boucquey $D$ and Baravelli $\mathrm{M}$ to be the commonest preceding illness. ${ }^{21,22}$ Pain was the chief complaint in our patients and 41 patients (54\%) reported pain in extremities which was the commonest site followed by pain in back which was reported by 38 patients $(50.6 \%)$. This was much higher than that cited in another Asian study (13.8\%) that was done in Taiwan. ${ }^{23}$

All cases included in our study had progressive motor limb weakness of acute onset. Neither case of pure acute cranial motor nerve involvement, nor any case of pure sensory GBS were noted in our series and we also did not identify any case of Miller Fischer variant this syndrome. Cranial nerve involvement is also common in patients with Guillian Barre syndrome and data is variable with reports showing involvement between $15 \%$ - $45 \%$. The presentations of cranial nerve involvement that we noted were dysphagia, dysarthria, ptosis and ophthalmoplegia. Overall the rate of cranial nerve involvement was higher in males than females. The high rate of cranial nerve involvement is similar to other reports by Cheng ${ }^{24}$ and Mickhann. ${ }^{25}$ Occurrence of autonomic dysfunction was also noted in our study and various symptoms of autonomic involvement like sinus tachycardia, sinus bradycardia, urinary dysfunction and constipation were noted. The commonest presentations were constipation and sinus tachycardia affecting $80 \%$ and $49 \%$ patients respectively. These findings were similar to those shown by Chinese, Taiwanese and American studies. ${ }^{12,13,26,27}$ Respiratory failure occurred $34.6 \%$ of patients out of which $20 \%$ were males and $14.6 \%$ females. All such patients required mechanical ventilation. Earlier smaller scale study by Ali and Suleman ${ }^{28}$ done in Peshawar also showed respiratory involvement in $28.6 \%$ of patients. The prognosis of patients requiring assisted ventilation was not studied as this required transferal to a separate unit which had facilities of ventilator and data was not retrieved from there. Besides not being able to retrieve data of prognosis of patients who had respiratory failure, our study also had other limitation and that was not focusing on the treatment outcome and the long term follow up. The reason that we attribute to this is the shortage of time. It is known that GBS can lead to disability and to minimize the residual deficits, a multidisciplinary team is required which should ideally include a neurologist, a physician, an intensivist, a physiotherapist, speech therapist and occupational therapy professionals. There is variable data on outcome after treatment with the use of plasmapheresis or IV immunoglobulin. ${ }^{11}$

\section{CONCLUSION}

We can conclude that we have found GBS occurred at all ages and was more common in males. There are various clinical features of GBS observed along with flaccid limbs weakness \& these should be address promptly for better outcome.

\section{ACKNOWLEDGEMENT}

This is the dissertation based study.

Copyright (C) 25 Nov, 2018.

\section{REFERENCES}

1. Yuki N, Hartung HP. Guillain-Barre syndrome. N Engl J Med. 2012 June 14; 366(24):2294-304.

2. Frenzen PD. Economic cost of Guillain-Barre syndrome in the United States. Neurology. 2008; 71(1):21-7.

3. McGrogan A, Madle GC, Seaman HE, e Vries CS. The epidemiology of Guillain-Barre syndrome worldwide A systematic literature review. Neuroepidemiology. 2009; 32(2):150-63.

4. Ali M, Fernandez-Perez ER, Pendem S, Brown DR, Wijdicks EF, Gajic $O$. Mechanical ventilation in patients with Guillain-Barre syndrome. Respir Care. 2006; 51(12):1403-7.

5. Newswanger DL, Warren CR. Guillain-Barre syndrome. Am Fam Physician. 2004; 69(10):2405-10.

6. Wakerly BR, Yukin N. Infectious \& non infectious triggers in GBS. Expert Rev Clin Immunol. 2013 July; 9(7): 627-39.

7. Van den Berg, Vander Eijk AA, Pars SD et al. GBS associated with preceding hepatitis $E$ virus infection. Neurology. 2014 Feb 11; 82(6): 491- 7)

8. Tam CC, O'Brien SJ, Petersen I, Islam A, Hayward A, Rodrigues $L C$. Guillain-Barre syndrome and preceding infection with campylobacter, influenza and EpsteinBarr virus in the general practice research database. 
PLoS ONE. 2007; 2(4):e344.

9. Tam CC, Rodrigues LC, Petersen I, Islam A, Hayward A, O'Brien SJ. Incidence of Guillain-Barre syndrome among patients with campylobacter infection: a general practice research database study. J Infect Dis. 2006; 194(1):95-7.

10. Yakoob MY, Rahman A, Jamil B, Syed NA. Characteristics of patients with Guillain Barre Syndrome at a tertiary care centre in Pakistan, 19952003. J Pak Med Assoc. 2005; 55(11):493-96.

11. (Fockke C, Van deng Berg B, Drenthen J, Walgard C, Van Doom PA, Jacob BC. Diagnosis of GBS \& Validation of Brighton).

12. Mahalati K, Dawson RB, Collins JO, Lietman S, Pearlman S, Gulden D. Characteristics of 73 patients, 19841993, treated by plasma exchange for Guillain Barre Syndrome. J Clin Apheresis 1997; 12:116-21.

13. Lyu RK, Tang LM, Cheng SY, Hsu WC, Chen ST. Guillain-Barre syndrome in Taiwan: A clinical study of 167 patients. J Neurol Neurosurg Psychiatry 1997; 63:494-500.

14. Characteristics of patients with Guillain Barre Syndrome at a tertiary care centre in Pakistan, 19952003. Yaqoob MY, Rahman A, Syed NA. JPMA 2005; 55(11):493-6.

15. Kaplan JE, Schenberger LB, Hurwite ES, Katona P. GBS in the United States. 1978-81, additional observations from the national surveillance system. Neurology (Cleveland) 33:633-637, 1983.

16. Kennedy RH, Danielson MA, Mulder PW, Kurland LT. A 42 year epidemiologic and clinical study. Myo Clin. Proc., 53:93, 1978.

17. Ropper AH, Wijdicks EFM, Truax BT. Guillain-Barre syndrome. Philadelphia: FA Davis, 1991, pp. 113-21.

18. Sedano MJ, Calleja J, Canga E, Berciano J. Guillain barre syndrome in Cantabria, Spain. An epidemiological and clinical study. Acta Neurol Scand 1994; 89:287-92.
19. Massuci EF, Kurtzke JF. Diagnostic criteria for the Guillain Barre syndrome. An analysis of 50 cases. J Neurol Sci 1971; 13:483-501.

20. Larsen JP, Kvale G, Nyland H. Epidemiology of the Guillain Barre syndrome in the county of Hordaland, Western Norway. Acta Neurol Scand 1985; 71:43-7.

21. Boucquey D, Sindic CJM, Lamy M, Delmee M, Tomasi JP, Laterre EC. Clinical and serological studies in a series of $\mathbf{4 5}$ patients with Guillain Barre syndrome. J Neurol Sci 1991;104:56-63.

22. Baravelli M, Fantoni C, Rossi A. Guillain-Barré syndrome as a neurological complication of infective endocarditis. Is it really so rare and how often do we recognise it?. Int J Cardiol. Jan 10 2008; [Medline].

23. Nelson L, Gormley R, Riddle MS, Tribble DR, Porter CK. The epidemiology of Guillain-Barré Syndrome in U.S. military personnel: a case-control study. $B M C$ Res Notes. Aug 26 2009; 2:171. [Medline]. [Full Text].

24. Lyu RK, Tang LM, Cheng SY, Hsu WC, Chen ST. Guillain-Barre syndrome in Taiwan: A clinical study of 167 patients. J Neurol Neurosurg Psychiatry 1997; 63:494-500.

25. Cheng Q, Jiang GX, Press R, Andersson M, Ekstedt B, Vrethem M, et al. Clinical epidemiology of GuillainBarre syndrome in adults in Sweden 1996-97: A prospective study. Eur J Neurol 2000; 7:685-92.

26. Mckhann GM, Cornblath DR, Ho T, Li CY, Bai AY, Wu $\mathrm{HS}$, et al. Clinical and electrophysiological aspects of acute paralytic disease of children and young adults in northern China. The Lancet 1991; 338:593-97.

27. Alam TA, Chaudhry V, Cornblath DR. Electrophysiological studies in the Guillain Barre Syndrome: distinguishing subtypes by published criteria. Muscle Nerve 1998; 21:1275-9.

28. Ali G, Suleman S. Clinical presentations and outcome of patients with Guillain Barre syndrome. J Postgrad Med Inst 2006: 20(2); 164-9. 
Wise men speak because they have something to say; fools because they have to say something.

\section{"Plato"}

\section{AUTHORSHIP AND CONTRIBUTION DECLARATION}

\begin{tabular}{|c|c|c|c|}
\hline Sr. \# & Author-s Full Name & Contribution to the paper & Author $=\mathbf{s}$ Signature \\
\hline 1 & Shahid lqbal & Statistical analysis & \\
\hline 2 & Naeemullah Bullo & Writing manuscript & \\
\hline 3 & Dileep Kumar & Writing manuscript & \\
\hline 4 & Suneel Kumar & Statistical analysis & \\
\hline 5 & Munir Afzal & Collection of data & \\
\hline 6 & Vikash & Data collection & \\
\hline
\end{tabular}

